\title{
Tunable Characteristics of Ferrite Composite Right/left Handed Coplanar Waveguide Coupled Line Coupler - Measurement and Experimental Verification
} DOI:

10.1016/j.aeue.2018.09.022

\section{Document Version \\ Accepted author manuscript}

Link to publication record in Manchester Research Explorer

Citation for published version (APA):

Abdalla, M. A., \& Hu, Z. (2018). Tunable Characteristics of Ferrite Composite Right/left Handed Coplanar Waveguide Coupled Line Coupler - Measurement and Experimental Verification. AEU - International Journal of Electronics and Communications, 96, 113-121. https://doi.org/10.1016/j.aeue.2018.09.022

Published in:

AEU - International Journal of Electronics and Communications

\section{Citing this paper}

Please note that where the full-text provided on Manchester Research Explorer is the Author Accepted Manuscript or Proof version this may differ from the final Published version. If citing, it is advised that you check and use the publisher's definitive version.

\section{General rights}

Copyright and moral rights for the publications made accessible in the Research Explorer are retained by the authors and/or other copyright owners and it is a condition of accessing publications that users recognise and abide by the legal requirements associated with these rights.

\section{Takedown policy}

If you believe that this document breaches copyright please refer to the University of Manchester's Takedown Procedures [http://man.ac.uk/04Y6Bo] or contact uml.scholarlycommunications@manchester.ac.uk providing relevant details, so we can investigate your claim.

\section{OPEN ACCESS}




\title{
Tunable Characteristics of Ferrite Composite Right/left Handed Coplanar Waveguide Coupled Line Coupler - Measurement and Experimental Verification
}

\author{
Mahmoud A. Abdalla ${ }^{1}$ and Zhirun $\mathrm{Hu}^{2}$ \\ ${ }^{1}$ Electromagnetic Field Group, Electronic Engineering Department, MTC College, Cairo, \\ Egypt,maaabdalla@mtc.edu.eg,maaabdalla@ieee.org \\ ${ }^{2}$ Microwave and Communications systems Group, School of Electrical \& Electronic \\ Engineering, University of Manchester, P.O Box 88, Manchester M60 1QD, UK, \\ z.hu@manchester.ac.uk
}

This paper presents the experimental verification of the tunable characteristics of a ferrite composite right/left handed coupled line coupler. The coupler is designed using two coupled CRLH-CRLH transmission lines. The coupler is designed to demonstrate equal through and backward coupling. The novel coupler has been designed and realized in coplanar waveguide configuration on a ferrite substrate. The tunable characteristics are achieved by changing the applied DC magnetic bias to the ferrite substrate. The measurement results reveal that the coupler's fractional bandwidth can be tuned from $29 \%$ to $69 \%$ by varying the applied DC magnetic bias from 1000 Oe to 1750 Oe. Within the tunable bandwidth, the maximum backward coupling is $-5 \mathrm{~dB}$. The coupler has high forward coupling isolation, close to $-30 \mathrm{~dB}$ at its centre operating frequency. In addition to its tuning capability, the coupler has the advantages of its compact size; it has the length of $11.5 \mathrm{~mm}$ and not-so-tight line separations of $2.5 \mathrm{~mm}$. Furthermore the coupler only requires low DC magnetic bias.

Keywords: Ferrite circuits, left handed media, metamaterials. coupled line couplers

Corresponding author: M. A. Abdalla, email: maaabdalla@ieee.org.

\section{Introduction:}

In the past decade, artificial composite right/left handed transmission lines (CRLH) or negative refractive index (NRI) transmission lines have been proven to have unique novel properties. These lines have negative effective index of refraction that supports backward wave with slow wave propagation [1]-[3]. These lines are considered the planar version of artificial engineered media that commonly referred as metamaterial. Hence, these lines have been employed to design radio frequency microwave components and antennas. This includes compact / multiband / wideband impedance transformers [4], balun [5], power splitters [6], 
filters [7]-[9], couplers [10]-[13], amplifiers [14], resonant antennas [15]-[18], leaky wave antennas [19], ultra wide band antennas [20], MIMO antennas [21],[22] lenses [23] and tunable metasurfaces structures [24]. Precisely speaking about couplers, CRLH TL based couplers are characterized by unusual properties in conventional microwave couplers [1],[10]. In general, the size of a coupled line coupler (CLC) depends on the operation frequency; the lower the frequency, the larger the size. This is because the length of the two coupled lines of the coupler must have electrical length of $90^{\circ}$, i.e., $\lambda / 4$ physical length. If the two coupled lines are made of CRLH TLs, the physical length of the lines can be much smaller than $\lambda / 4$, hence much smaller coupler can be realize. The analysis of the backward CRLH CLC has revealed that the backward coupling lies within the stopband coupled mode propagation constants. Consequently, the backward coupling will not be related to the electrical length, but with the attenuation length of the coupled lines. Therefore, CRLH backward CLC can achieve arbitrary coupling level up to $0 \mathrm{~dB}$ [10].

In order to achieve nonreciprocal and tuning functionalities, CRLH TLs have been proposed on ferrite substrates. Ferrite substrate has a dispersive relative permeability which can be either positive or negative quantity according to the ferrite magnetization and the applied DC magnetic bias.

Therefore, CRLH TLs can acquire their properties depending on applied DC magnetic bias to the hosting ferrite substrate which can be either microstrip / coplanar waveguide in all frequency band regimes [25]-[30]. In this context, tunable resonators [31],[32], impedance transformers [33],[34], phase shifters [35],[36], diplexers [37], circulators [38], leaky wave antennas [39]-[41] and couplers [42]-[46] were suggested. Ferrite CRLH CLCs have proven to demonstrate new properties such as (1) the cut off frequencies of the negative ferrite permeability bandwidth can be used to determine the operational cut off frequencies of a compact CRLH backward CLC, (2) by controlling the DC magnetic bias direction and value, the ferrite CLC can also demonstrate tunable and nonreciprocity characteristics [44]. However, there is still lack of detailed discussion on the measurement setup and experimental results of CLCs.

In this paper we report newly fabricated ferrite CRLH CPW CLC on a YIG substrate and its experimental results. The presented coupler has been designed as two identical coupled CRLH on ferrite substrate on CPW configuration. The CPW configuration has been chosen because it requires smaller DC magnetic bias compared to other configurations due to its smaller demagnetization factor. The two coupled CRLH lines are synthesized using series 
interdigital capacitors and shunt meander line inductors with no via connection. By changing the applied DC magnetic bias, the propagation through the lines and coupling coefficient are changing and hence a tuning effect is achieved. Measurements setup is explained in details and tuning properties are presented for different DC magnetic bias.

\section{Theory and Design Principles}

The coupled mode equations for the forward and backward modes along the symmetrical CRLH CLC shown in Fig. 1 can be given as [10]

$$
\begin{aligned}
& \frac{\partial V_{1}^{+}}{\partial z}=-j \beta_{L H} V_{1}^{+}+j C_{B W} V_{2}^{-}-j C_{F W} V_{2}^{+} \\
& \frac{\partial V_{2}^{-}}{\partial z}=+j \beta_{L H} V_{2}^{-}-j C_{B W} V_{1}^{+}+j C_{F W} V_{1}^{-} \\
& \frac{\partial V_{1}^{-}}{\partial z}=+j \beta_{L H} V_{1}^{-}-j C_{B W} V_{2}^{+}+j C_{F W} V_{2}^{-} \\
& \frac{\partial V_{2}^{+}}{\partial z}=-j \beta_{L H} V_{2}^{+}+j C_{B W} V_{1}^{-}-j C_{F W} V_{1}^{+}
\end{aligned}
$$

where $\mathrm{V}_{n}{ }^{+}$and $\mathrm{V}_{n}{ }^{-}$, with subscript $n=1,2$ referring to the parallel lines 1 and 2 respectively, are the forward propagation and backward coupled mode waves, $\beta_{C R L H}$ the propagation constant of the individuals CRLH lines, $C_{B W}$ the backward coupling coefficient, and $C_{F W}$ the forward coupling coefficient defined as

$$
\begin{aligned}
& C_{B W}=\beta_{R H}\left(\frac{\kappa_{e}+\kappa_{m}}{2}\right) \\
& C_{F W}=\beta_{R H}\left(\frac{\kappa_{e}-\kappa_{m}}{2}\right)
\end{aligned}
$$

where $\beta_{\mathrm{RH}}$ is the propagation constant of the corresponding $\mathrm{RH}$ section contribution of the coupled CRLH TL, $\kappa_{e}$ and $\kappa_{m}$ the electric and magnetic coupling coefficients, respectively, defined in terms of the mutual inductance $\left(L_{m}\right)$, the mutual capacitance $\left(C_{e}\right)$, the right handed inductance $\left(L_{R}\right)$, and the right handed capacitance $\left(C_{R}\right)$ as

$$
\begin{gathered}
\kappa_{m}=\frac{L_{m}}{L_{R}} \\
\kappa_{e}=\frac{C_{e}}{C_{R}}
\end{gathered}
$$

According to the value and sign of the previous magnetic coupling coefficient, the mechanism of the CRLH CLC is established. Consequently, a typical backward coupler has positive $\kappa_{m}$ equal to $\kappa_{e}$, requiring a positive mutual inductance described as 


$$
\kappa_{m}=\kappa_{e} \Rightarrow L_{m}=\frac{L_{R}}{C_{R}} C_{e}
$$

Also, the backward coupling coefficient is described as

$$
C_{B W}=\frac{L_{m}}{L_{R}} \beta_{R H}
$$

It has been shown in [28] that the negative permeability of a ferrite planar TL can represent a negative series parasitic inductive load, numerically, within its frequency bandwidth. Therefore, the magnetic coupling coefficient, $\kappa_{\mathrm{m}}$, between two planar parallel coupled TLs will change in sign and magnitude within this frequency bandwidth. As a result, the coupling mechanism of a planar CRLH CLC designed on ferrite substrate will be frequency dependent according to the applied DC magnetic bias.

Within the frequency band characterized by a positive permeability of the individual hosting ferrite TL $\left(\mu_{\mathrm{f}}\right)$, the parasitic inductance of individual CRLH TLs is positive, like conventional TLs, and hence the coupler can demonstrate positive magnetic coupling coefficient $\left(\kappa_{\mathrm{m}}\right)$. Then the CLC can be designed as a typical backward coupler by the proper design of the individual TL elements, the mutual inductance and capacitance. However, the through propagation of a ferrite CLC is possible without any frequency band restriction, depending on the design requirements. Moreover, it has nonreciprocity propagation characteristics within the negative permeability frequency band of the hosting ferrite individual TLs depending on the propagation direction and the applied DC magnetic bias direction.

The coupler frequency band has been selected to be within the left handed frequency band of each individual coupled line. In other words, the coupler lower cut off frequency is higher that the lower left handed cut off frequency $\left(\mathrm{f}_{\mathrm{cl}}\right)$ of each individual couple TL obtained. The upper cut off frequency of the CLC is designed to be at the onset where the substrate permeability becomes negative. By changing the applied DC magnetic bias, the bandwidth of the CLC can be tuned. 


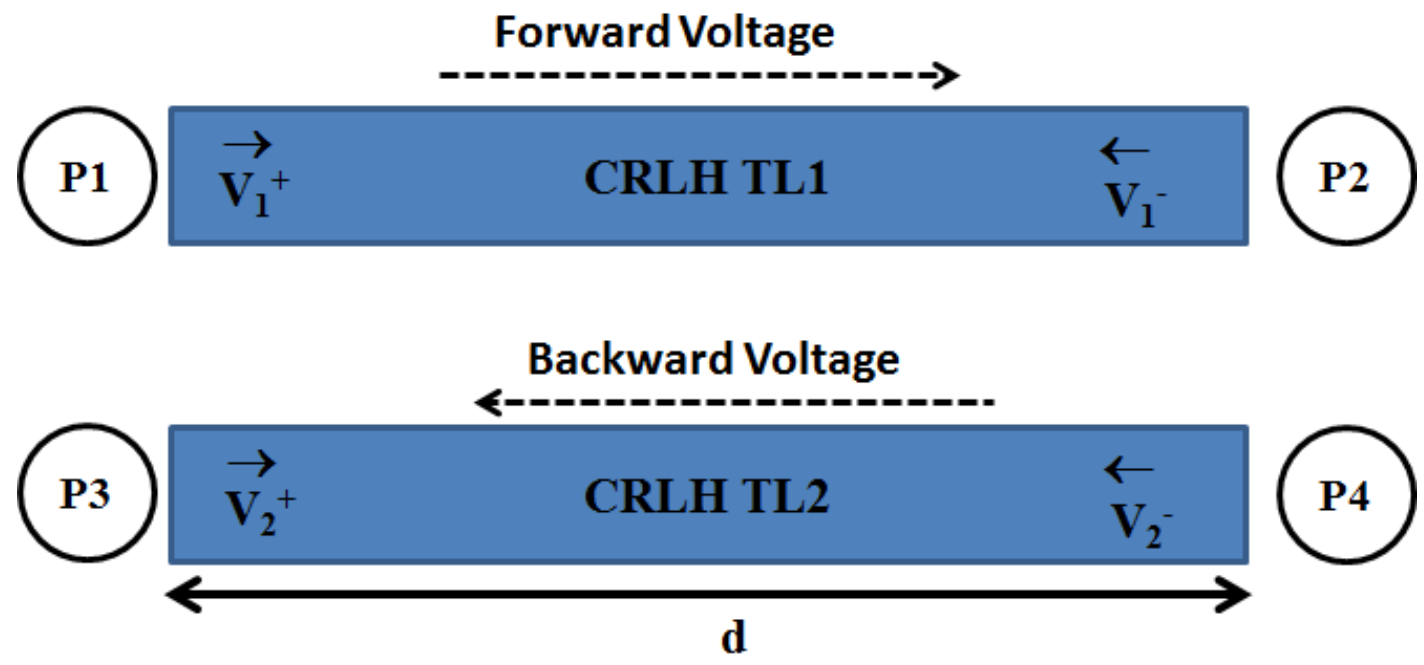

Fig. 1 The forward and backward voltage waves along the coupled-lines

\section{Structure, Design and Fabrication}

\section{a) The CRLH Coupler Structure}

The vertical cross section for the coupler is shown in Fig. 2. The ferrite substrate is YIG Trans-Tech TTVG-1850 with with substrate thickness $(\mathrm{h})=1 \mathrm{~mm}, \varepsilon_{\mathrm{f}}=14.8, \tan \delta<0.0002$, saturation magnetization $4 \pi \mathrm{M}_{S}=1850$ Gauss, and magnetic linewidth $\Delta \mathrm{H}_{0} \leq 10$ Oe. An internal DC magnetic field $\left(\mathrm{H}_{0}\right)$ is applied to the ferrite substrate in the shown direction in Fig. 2 causing the ferrite substrate to have the saturation magnetization in the same direction. For the shown direction of DC magnetic bias, the demagnetization effect is small as the cross-section area facing the DC magnetic bias direction (along $\mathrm{X}$ direction) is very small. This can be understood well if a comparison case to microstrip the DC magnetic bias in which the DC magnetic bias should directed to a large area which is area along the Y direction. For this DC magnetic bias direction, the relative permeability tensor is [44]

$$
[\mu]=\left[\begin{array}{ccc}
1 & 0 & 0 \\
0 & \mu & j k \\
0 & -j k & \mu
\end{array}\right]
$$

where

$$
\begin{array}{r}
\mu=\frac{\omega_{h m}^{2}-\omega^{2}}{\omega_{h}^{2}-\omega^{2}} \\
k=\frac{\omega \omega_{m}}{\omega_{h}^{2}-\omega^{2}}
\end{array}
$$

where the Larmor frequency (gyromagnetic resonance frequency, $\omega_{h}$ ), the magnetization frequency $\left(\omega_{m}\right)$, and $\left(\omega_{h m}\right)$ are defined as 


$$
k=\frac{\omega \omega_{m}}{\omega_{h}^{2}-\omega^{2}}
$$

Also, the equivalent relative ferrite permeability of the ferrite hosting CPW TL $\left(\mu_{\mathrm{f}}\right)$ is equal to $\left(\mu_{\mathrm{fn}}\right)$ defined as

$$
\mu_{f n}=\mu
$$

This equivalent permeability is negative within the frequency range $f_{n l}<f<f_{n h}$ where $f_{n l}$ and $\mathrm{f}_{\text {nh }}$ were calculated using equations (16) and (17), respectively.

$$
\begin{gathered}
f_{n l}=\frac{1}{2 \pi} \omega_{h} \\
f_{n h}=\frac{1}{2 \pi} \omega_{h m}
\end{gathered}
$$

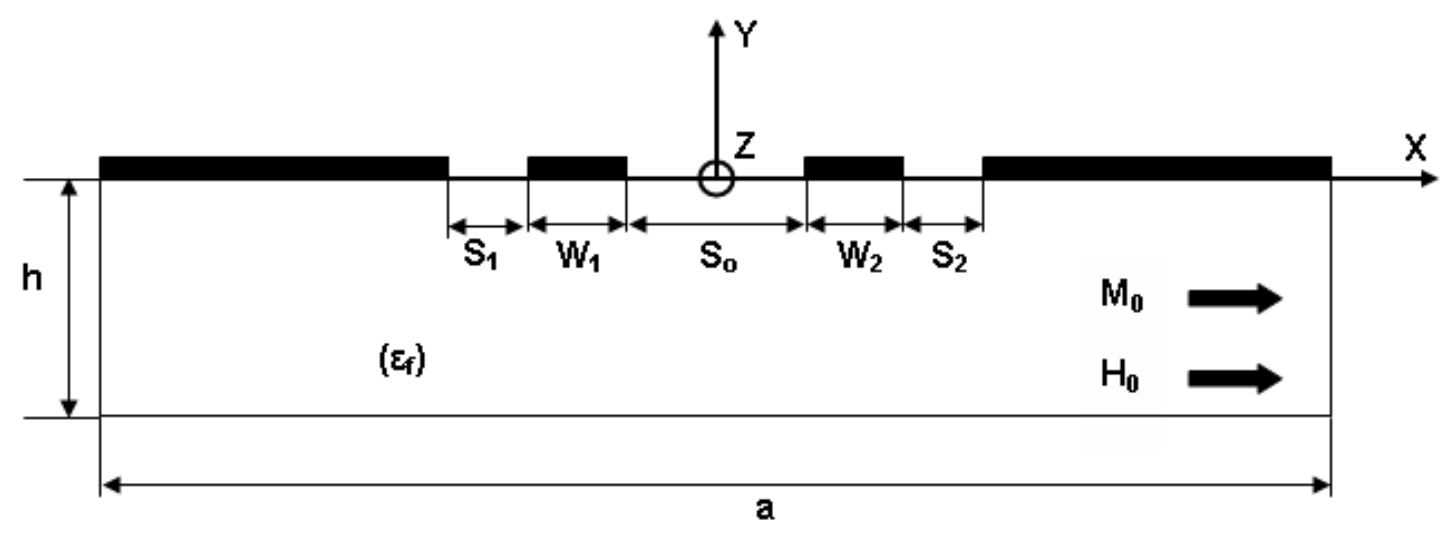

Fig. 2 The vertical cross section of the all CRLH CPW CLCs.

The layout diagram of the horizontally magnetized ferrite CRLH CPW CLC is shown in Fig. 3 (a). The CPW CLC was designed using two identical CRLH TLs separated by a distance $\mathrm{S}_{\mathrm{o}}$. Each individual CRLH TL was designed by loading the hosting ferrite CPW TL periodically with a shunt meandered line inductor and series interdigital capacitor in two unit cell configurations. For the matching purpose, different configurations of the two interdigital capacitors at input/output ports and the internal capacitor are used. The shunt inductive load is formed by a meandered line inductor with only two meandered arms. The detailed dimensions of the loading elements are shown in Fig. 3 (b and c). The loading and parasitic element dimensions were chosen to satisfy the design requirements. The feeding extension CPW TL dimensions at each port of the CPW coupler are identical such that they represent a $50 \Omega$ TL. 


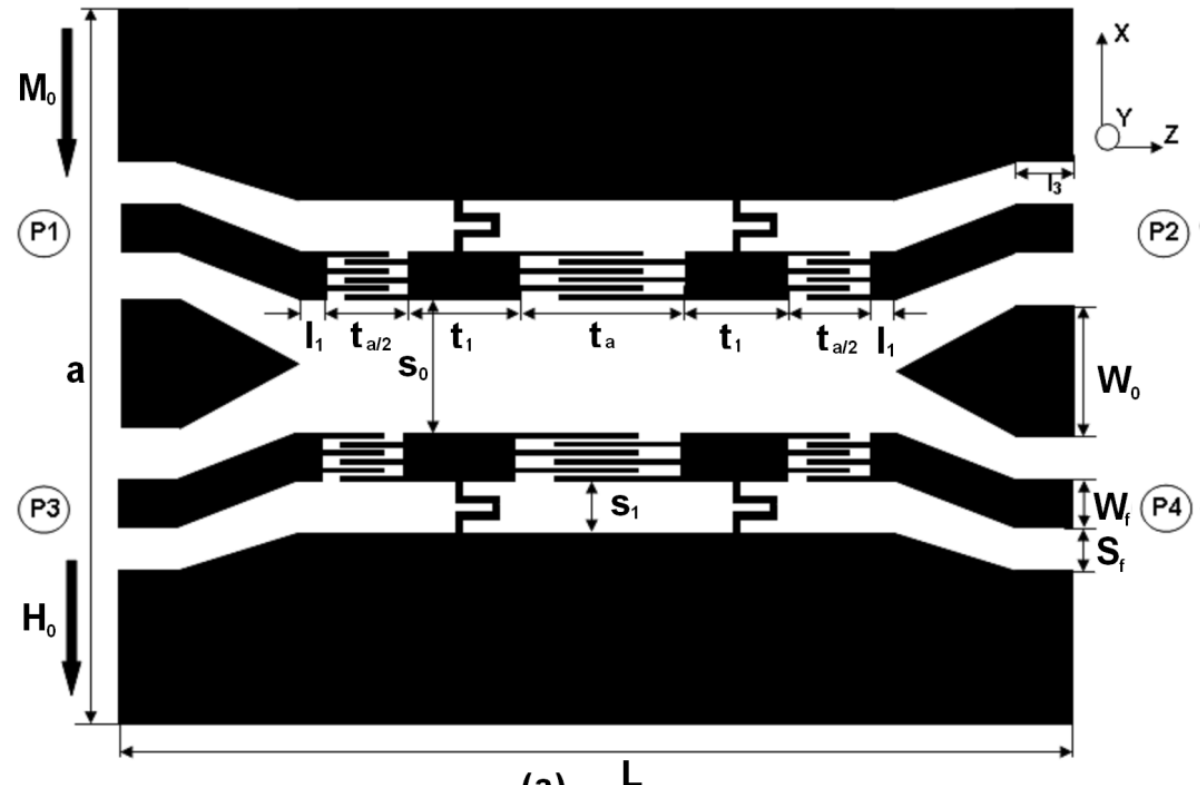

(a)

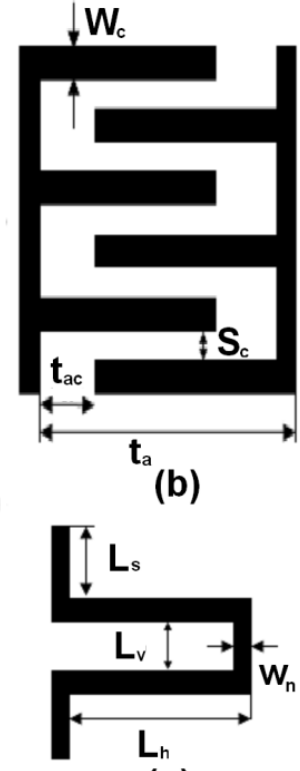

(c)

Fig. 3. (a) layout of the ferrite CRLH CPW coupled line coupler, $a=20 \mathrm{~mm}, \mathrm{~L}=11.5 \mathrm{~mm}$, $\mathrm{W}_{0}=6 \mathrm{~mm}, \mathrm{t}_{\mathrm{a}}=2.06 \mathrm{~mm}, \mathrm{t}_{1}=1.5 \mathrm{~mm}, \mathrm{l}_{1}=0.25 \mathrm{~mm}, \mathrm{l}_{3}=1.5 \mathrm{~mm}, \mathrm{~S}_{1}=1.25 \mathrm{~mm}, \mathrm{~S}_{0}=2.5$ $\mathrm{mm}, \mathrm{S}_{\mathrm{f}}=0.8 \mathrm{~mm}, \mathrm{~W}_{\mathrm{f}}=1.3 \mathrm{~mm}$, (b) details of the inter digital capacitor $\mathrm{S}_{\mathrm{c}}=\mathrm{W}_{\mathrm{c}}=0.1 \mathrm{~mm}$ and $t_{a c}=0.4 \mathrm{~mm}(\mathrm{c})$ details of the meandered line inductor $\mathrm{W}_{\mathrm{m}}=0.25 \mathrm{~mm}, \mathrm{~L}_{\mathrm{s}}=0.25 \mathrm{~mm}, \mathrm{~L}_{\mathrm{v}}$ $=0.25 \mathrm{~mm}$, and $\mathrm{L}_{\mathrm{h}}=0.5 \mathrm{~mm}$

\section{b) The CRLH Coupler Design Concept}

The backward mechanism of the CRLH coupler lies within the stopband of the individual CRLH transmission line. The initial design was to design a CRLH unit cell with a wide bandstop range that covers the objective frequency band of the coupler. The second design step was optimizing the coupler structure so that the coupling between the two CRLH lines coupling coefficient $\left(\mathrm{S}_{31}\right)$ is equal to the through coefficient $\left(\mathrm{S}_{21}\right)$.

The equivalent circuit of the used CRLH is shown in Fig. 4 (a) where $C_{L}$ is the employed interdigital capacitor (in Fig. 3 (a)) $\mathrm{L}_{\mathrm{L}}$ is the employed meander line inductor in Fig. (3 (b)). The elements $L_{R}$ and $C_{R}$ are accounted for the the patristic elements of the employed unit cell. The typical dispersion diagram of the CRLH unit cell is shown in Fig. 4 (b) where the frequency range of the designed stopband is highlighted. In our work, the bandstop frequency range from $\mathrm{f}_{\mathrm{c} 1}=3 \mathrm{GHz}$ to $\mathrm{f}_{\mathrm{c} 2}=7 \mathrm{GHz}$ is our intension coupler bandwidth so that it becomes suitable for wideband coupler design. These two frequencies can be 
calculated as

$$
\begin{aligned}
& f_{c 1}=\min \left(\frac{1}{2 \pi} \frac{1}{\sqrt{L_{L} C_{R}}}, \frac{1}{2 \pi} \frac{1}{\sqrt{L_{R} C_{L}}}\right) \\
& f_{c 2}=\max \left(\frac{1}{2 \pi} \frac{1}{\sqrt{L_{L} C_{R}}}, \frac{1}{2 \pi} \frac{1}{\sqrt{L_{R} C_{L}}}\right)
\end{aligned}
$$

This can be verified using circuit simulation (employing Advanced design system (ADS)) for the two designed CRLH cells coupled (electrical coupling coefficient $\left(k_{e}\right)=0.8$ and magnetic coupling coefficient $\left(k_{m}\right)=0.5$ ) as shown in Fig. $4(\mathrm{c})$. It is obvious that the one cell coupler has almost equal $S_{21}=S_{31}$ within the frequency band $3 \mathrm{GHz}-6 \mathrm{GHz}$. These results will be used as a start point for the synthesis of the coupled CRLH cells.

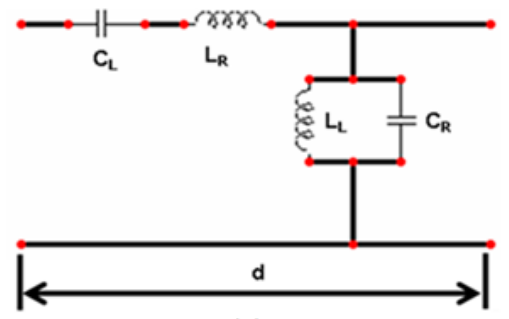

(a)

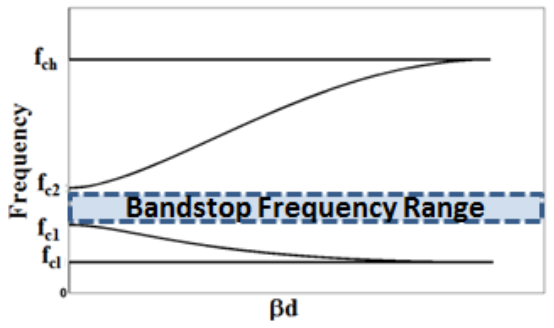

(b)

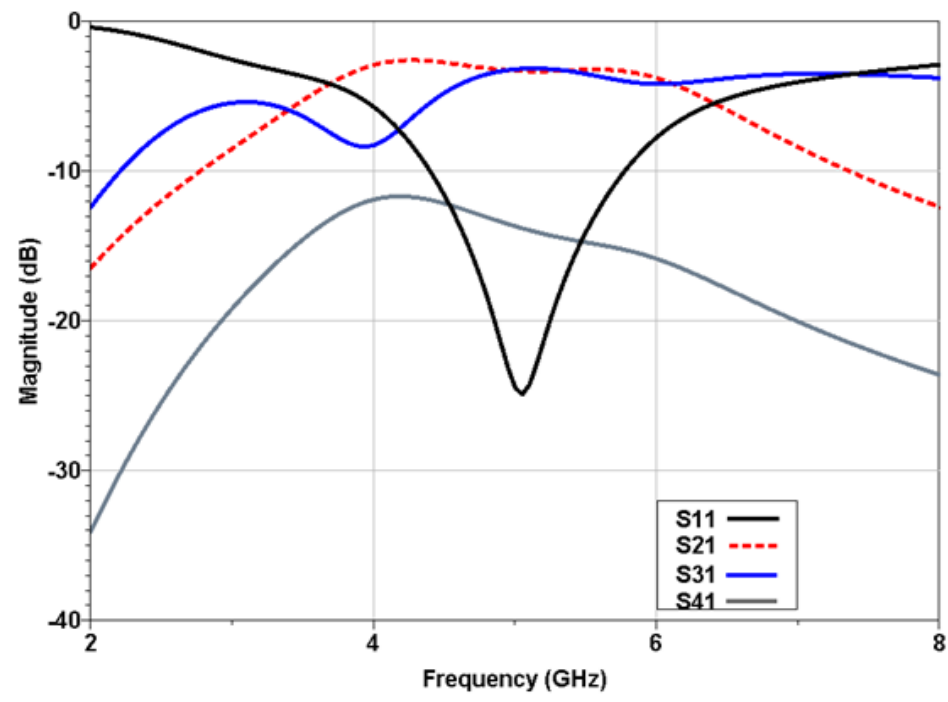

(c)

Fig. 4. (a) The circuit model for one CRLH cell $\left(\mathrm{L}_{\mathrm{R}}=1.8 \mathrm{nH}, \mathrm{C}_{\mathrm{R}}=2.4 \mathrm{pF}, \mathrm{C}_{\mathrm{L}}=1.05 \mathrm{pF}\right.$ and $\mathrm{L}_{\mathrm{L}}=0.35 \mathrm{nH}$ ), (b) The typical dispersion diagram of the used CRLH unit cell, (c) The simulated scattering parameter magnitudes of the designed CRLH unit cell coupler.

\section{c) The CRLH Coupler Design Concept}

The circuit fabrication process was carried out by wet etching to remove the unwanted parts on the metallization and hence to form the circuit patterns required. First, a photoresist protecting layer was spun on the top of the metallization layer and patterns were developed using lithography process. Second, the unwanted parts on the silver layer were removed by 
wet etching solution $\left(\mathrm{NH}_{4} \mathrm{OH}: \mathrm{H}_{2} \mathrm{O}_{2}: \mathrm{H}_{2} \mathrm{O}=1: 1: 4\right)$. Finally, the photoresist was dissolved by acetone. The fabricated ferrite CRLH CPW CLC is shown in Fig. 5 (a) where the YIG substrate and the FR4 layer cover can be seen. In Fig. 5 (b), two FR4 layer were added to the fabricated circuit for the sake of physically supporting the circuit while measurements as will be pointed out in next section.

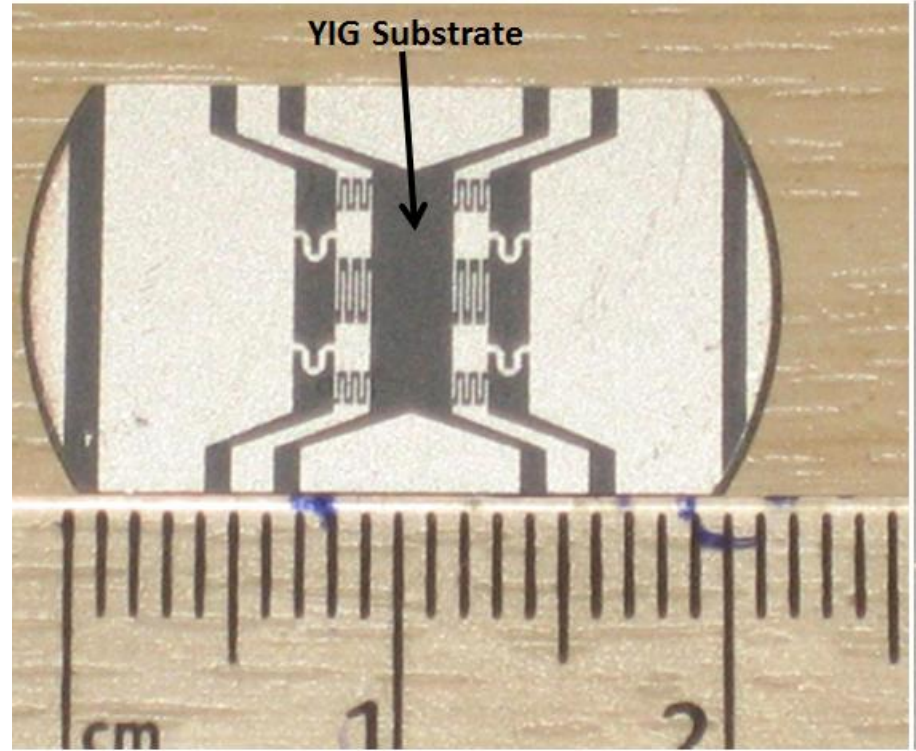

(a)

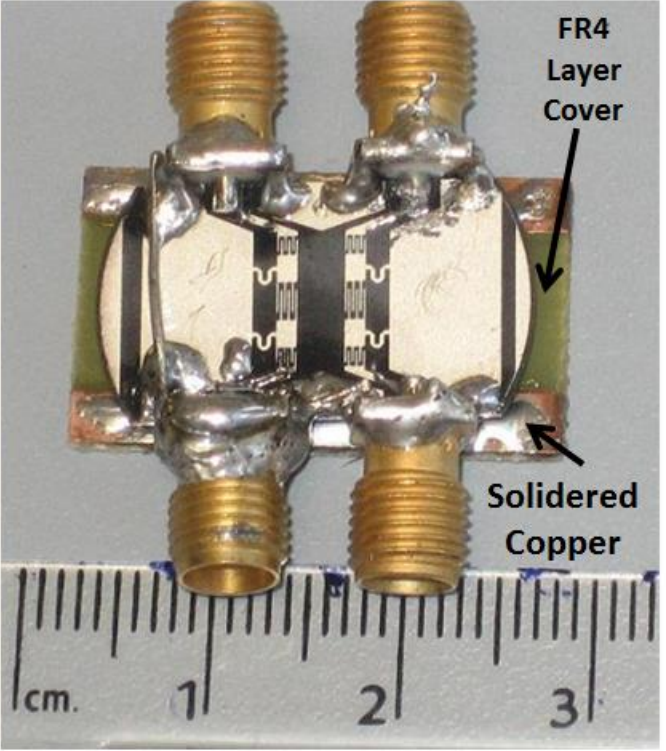

(b)

Fig. 5 The fabricated ferrite CRLH CPW coupled line coupler (a) the circuit prototype (b) the circuit with SMAs

\section{Experimental Results and Discussion}

The measurement setup is shown in Fig. 6. During the measurement the external DC magnetic bias values were set to compensate the effect of the in-plane demagnetization field, even though it has a small effect for a CPW configuration. The relation between the internal DC magnetic bias $\left(\mathrm{H}_{0}\right)$ and the external one $\left(\mathrm{H}_{\mathrm{ex}}\right)$ can be expressed as [47]

$$
H_{e x}=H_{0}+4 \pi M_{S} N
$$

where $\mathrm{N}$ is the demagnetization factor for the applied DC magnetic bias. In our case, this demagnetization factor for $\mathrm{CPW}$ configuration was calculated to be $\mathrm{N}=0.05$. Accordingly, a demagnetization field of 90 Oe representing the difference between the external DC magnetic field and the internal one was considered. It is worth to point out that, the demagnetization field was assumed to be uniform in our calculation.

The scattering parameters of the coupler were measured using Hewlett Packard 85107A VNA System. The required applying DC magnetic bias was generated using GMW Magnets 
Systems 5403 electromagnet. The applied DC magnetic bias was measured using the Magnetic Instruments LTD Gauss meter GM04.

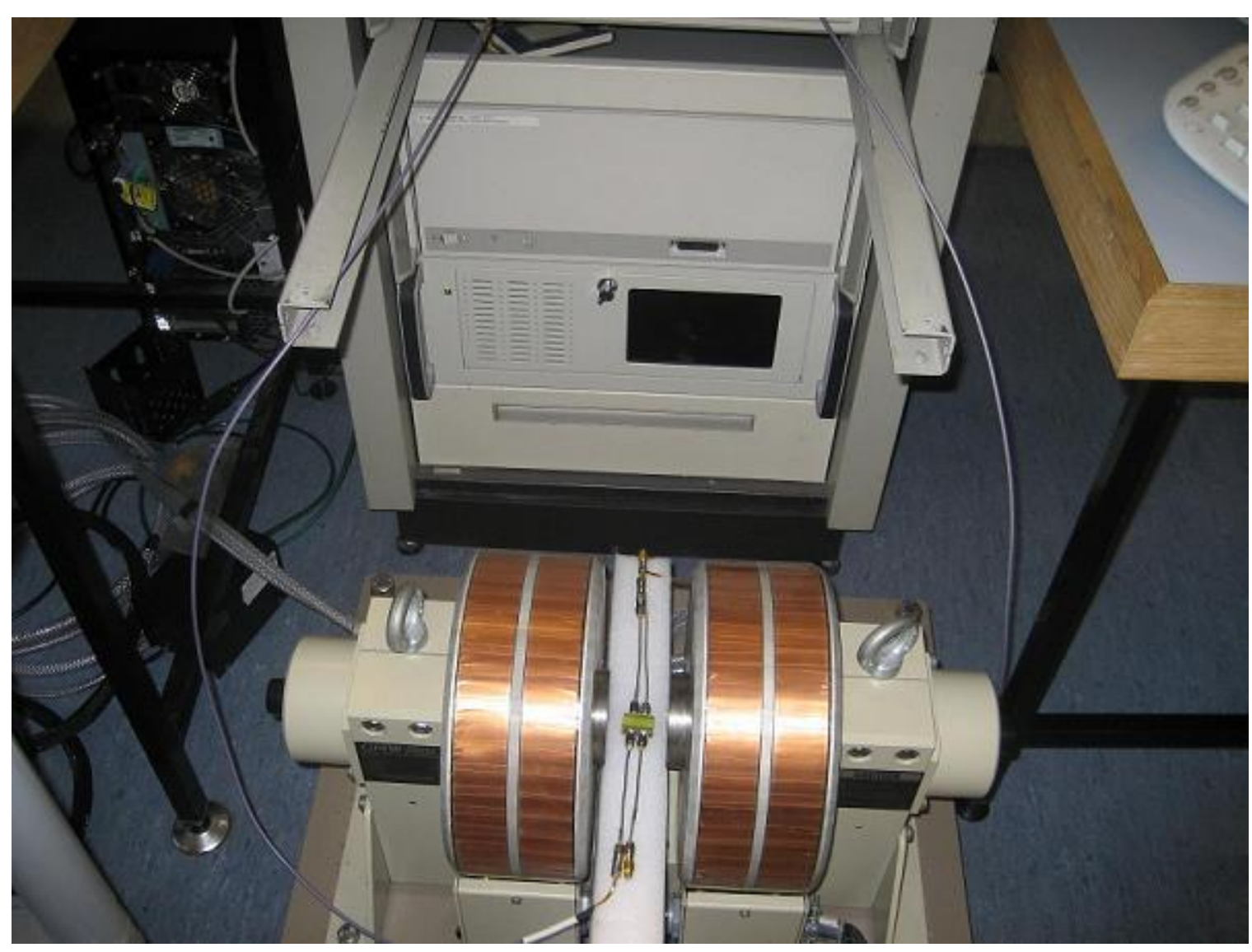

Fig. 6 The measurement setup of the tunable coupler using an electromagnet and VNA.

To avoid damaging the circuit during the measurement (the YIG substrate is very fragile), two horizontal upper and lower FR4 PCB board covers with thickness of $1.5 \mathrm{~mm}$ were soldered to the SMA bases at both input and output to give a physical strength to the circuit and prevent the input/output pads to be taken off. The dielectric FR4 has been chosen as lower and upper covers to eliminate the effects of metal covers as the device was designed assuming there was no covers.

The fabricated CRLH CPW CLC was measured first at $\mathrm{H}_{0}=3500$ Oe, the highest possible DC magnetic bias the Magnet can provide. Under high DC magnetic bias, the onset frequency at which the permeability of the ferrite substrate becomes negative is shifted to a very high frequency and hence the ferrite substrate can be considered isotropic within the frequency band of interest. Thus, the isotropic performance of the fabricated CLC can be assumed. Although this very high DC magnetic bias is not within the tuning DC magnetic bias range, this measurement has two goals: (a) to confirm that the coupler works properly 
when the substrate permeability is positive and (b) to differentiate between the coupler response for positive ferrite permeability, associated with this high DC magnetic bias, and that of negative ferrite permeability, associated with lower DC magnetic to be used later.

The measured scattering parameters at $\mathrm{H}_{0}=3500$ Oe are shown in Fig. 7. It is quite clear that the coupler has backward coupling level better than $10 \mathrm{~dB}$ from $2.9 \mathrm{GHz}$ to $5.9 \mathrm{GHz}$. Within this frequency band, both backward coupling and through propagation levels are close to each other $(10 \pm 2) \mathrm{dB}$. The high through level indicates that the ferrite substrate has positive permeability within the frequency band since the through will not be possible if the permeability is negative. The isolation reaches about $40 \mathrm{~dB}$ at $4.9 \mathrm{GHz}$ and sharply degrades before and after this frequency. The narrow band high isolation around $4.9 \mathrm{GHz}$ is probably because that the electrical length at this frequency point just reaches it length at which the minimum forward coupling occurs.

To demonstrate the tunability, the LH CPW CLC was measured for $\mathrm{H}_{0}=1500$ Oe and 1250 Oe and their scattering parameters are shown in Fig. 8 and Fig. 9, respectively. At $\mathrm{H}_{0}=1500$ Oe, it can be observed from Fig. 8 that the bandwidth for the through and backward coupling signals (both better than $10 \mathrm{~dB}$ ) is from $2.7 \mathrm{GHz}$ to $5 \mathrm{GHz}$, approximately, giving a fractional bandwidth of $60 \%$. The backward coupling level is between $-6 \mathrm{~dB}$ to $-10 \mathrm{~dB}$ within this band. It attenuates to less than $-20 \mathrm{~dB}$ at $5.5 \mathrm{GHz}$. The through propagation is almost constant with an approximate average of $-9 \mathrm{~dB}$. It starts attenuating after $5 \mathrm{GHz}$ and becomes less than -20 $\mathrm{dB}$ at $5.9 \mathrm{GHz}$. It can be commented that the upper cut off frequency, $5 \mathrm{GHz}$ is determined by the ferrite resonance frequency below which the ferrite permeability is positive.

At $\mathrm{H}_{0}=1250$ Oe, as shown in Fig. 9, the bandwidth for the through and backward coupling signals (both better than $10 \mathrm{~dB}$ ) has changed to be from $2.7 \mathrm{GHz}$ to $4.4 \mathrm{GHz}$, i.e., the fractional bandwidth has reduced to $48 \%$. The backward coupling level is between $-5 \mathrm{~dB}$ to $9 \mathrm{~dB}$ within this band. The through level is again almost constant around $-9 \mathrm{~dB}$. Above 4.4 $\mathrm{GHz}$ the through signal decays dramatically to be close to $-20 \mathrm{~dB}$ at $5 \mathrm{GHz}$. Meanwhile, the backward coupling is around $-10 \mathrm{~dB}$ until $4.7 \mathrm{GHz}$ and then it also attenuates to less than -20 $\mathrm{dB}$ at $5 \mathrm{GHz}$. The decay for both signals is due to the fact that wave can't propagate within the frequency band where the permeability is negative. We can explain that decreasing the upper cut off frequency to $4.4 \mathrm{GHz}$, compared to previous case, is due to the decrease of the ferrite resonance frequency by decreasing $\mathrm{H}_{0}$ to 1250 Oe.

It can be observed, in both cases, that the lower cut off frequency of the ferrite coupler changes little with DC magnetic bias. The lower cut off frequency for all studied cases within 
the ferrite positive permeability band, below the resonance frequency. It is worth to comment that the positive ferrite permeability below the resonance is frequency dependent, but this dependence is more significant around the ferrite resonance frequency. Since the lower cut off frequency (approximately $2.7 \mathrm{GHz}$ in studied cases) is not so close to the resonance frequency in studied cases, thus the ferrite positive permeability is almost close to unity in those cases. However, slight variations can be observed for the scattering $S_{21}, S_{31}$, and $S_{41}$ around $2.7 \mathrm{GHz}$ in studied cases. On the other hand, the upper cut off frequency increases with increasing DC magnetic bias, $\mathrm{H}_{0}$. This is because the onset frequency of negative ferrite permeability increases as DC magnetic bias increases. The direct result of this bias dependent onset frequency is that the bandwidth of the CLC can be tuned accordingly by DC magnetic bias.

It is worth to mention that all presented measurements have high value for $S_{11}$ which can be explained due to the effect of the FR4 cover layer configuration which unfortunate was very urgent for avoiding circuit damage while measurements. Apart of that high reflection level, the figure illustrates that the proposed coupler has tunable bandwidth by changing the DC bias. Enhancement in $\mathrm{S}_{11}$ can be done in the future by considering a good packaging technique which is out of the scope of this paper.

The variation of the fractional bandwidth of the CLC against the DC magnetic bias is shown in Fig. 10. It is clearly evident that the fractional bandwidth can be tuned from $29 \%$ at $\mathrm{H}_{0}=$ 1000 Oe to $69 \%$ at $\mathrm{H}_{0}=1750$ Oe. It is also obvious in all the cases that the return loss of the fabricated CRLH CPW CLC is relatively high. This is mainly caused by the mismatch between the ports of the coupler and the SMAs. However, this high return loss should not detract from the message being conveyed - experimentally verifying the tunability of the ferrite CRLH CPW CLC. Detailed measurement results for Fig. 8 were presented in [48].

Finally, for comparing the size, our proposed coupler length has been compared to recent published work for PCB $3 \mathrm{~dB}$ coupler as listed in Table 1. The proposed coupler has competitive size and bandwidth compared to non tunable couplers. However, the proposed coupler has clear small size advantage compared to other tenability technique. 


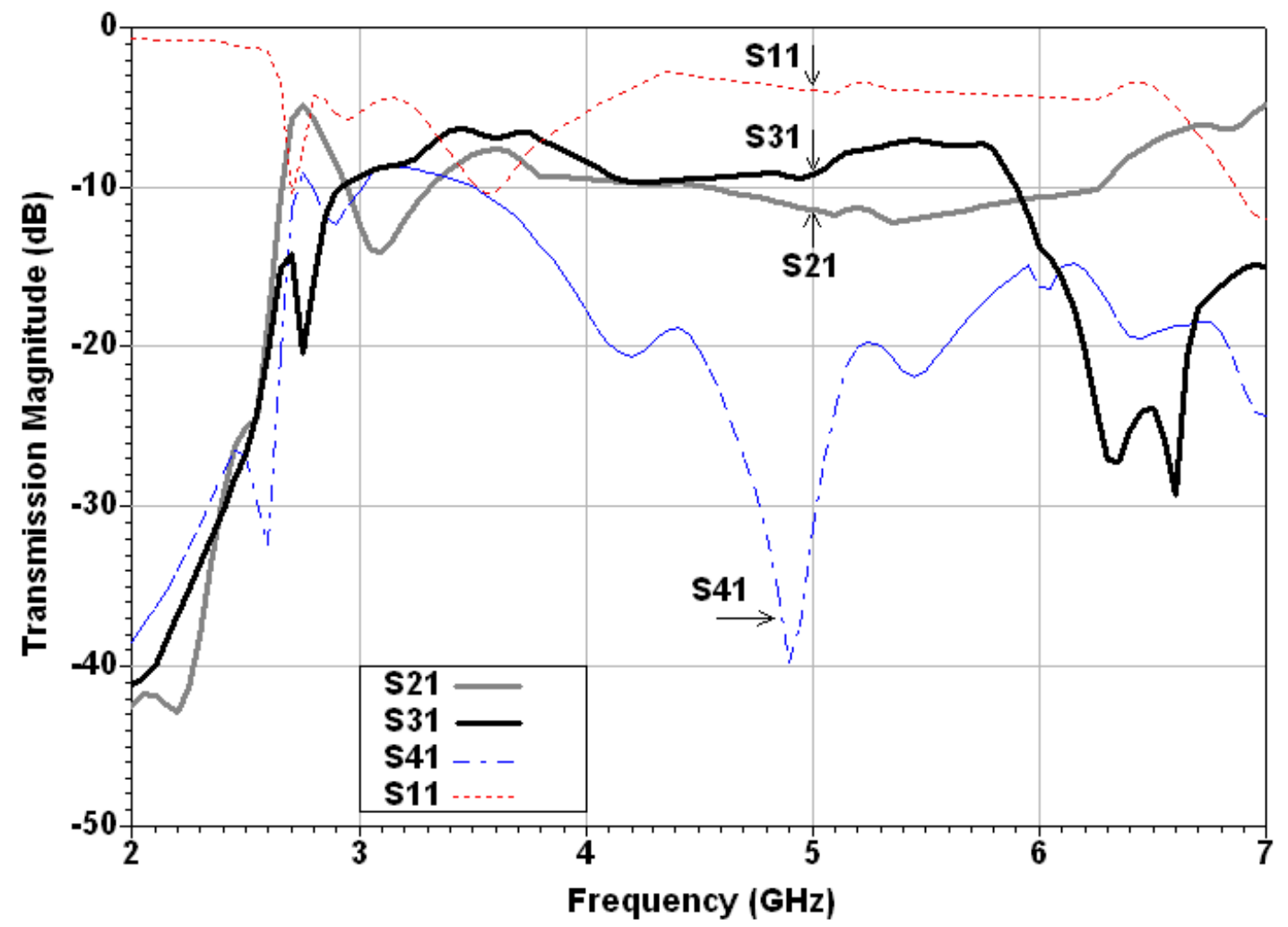

Fig. 7. The measured scattering parameters magnitudes of the ferrite CRLH coupled line coupler for $\mathrm{H}_{0}=3500 \mathrm{Oe}$.

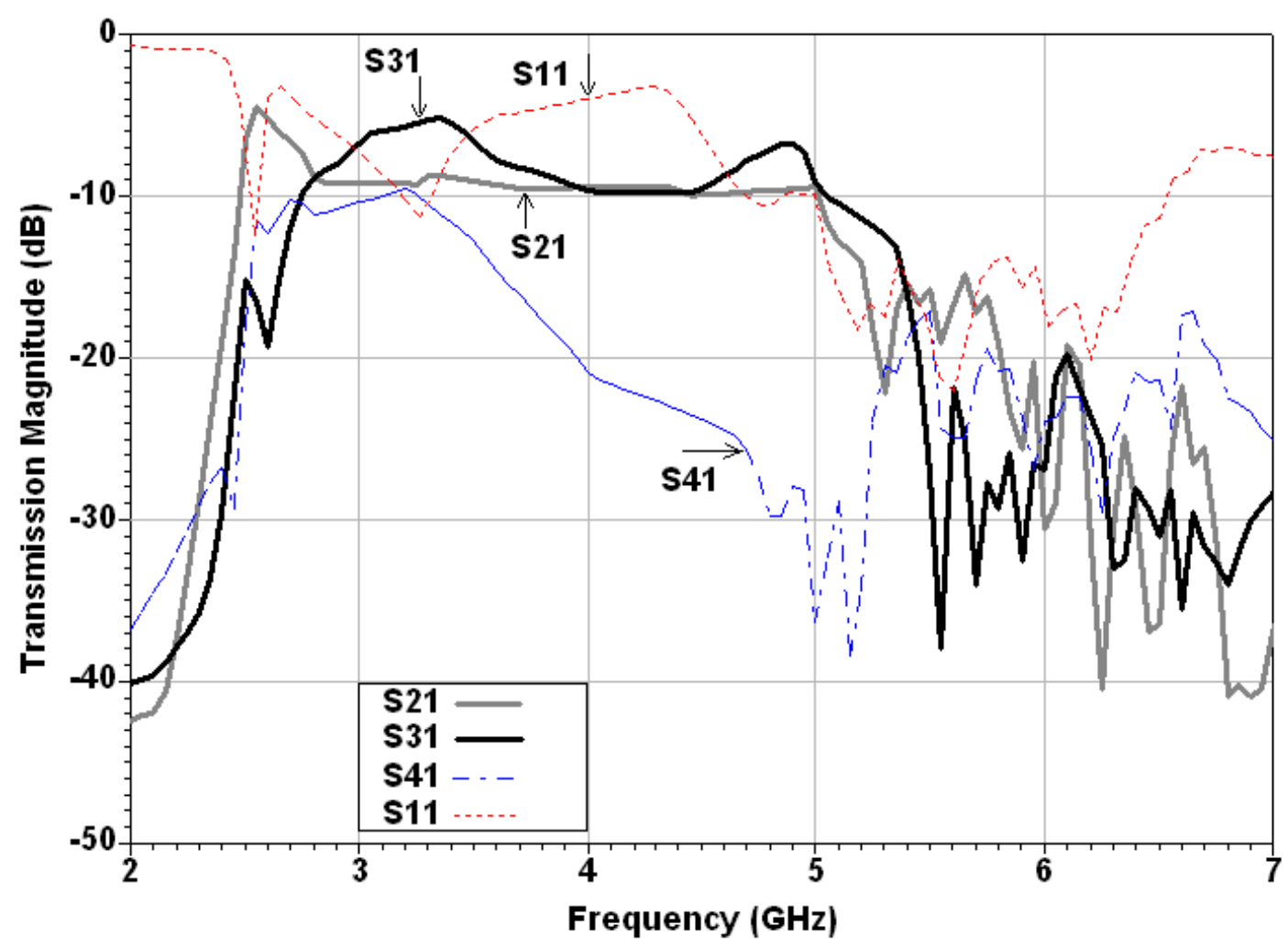

Fig. 8. The measured scattering parameters magnitudes of the ferrite CRLH coupled line coupler for $\mathrm{H}_{0}=1500$ Oe. 


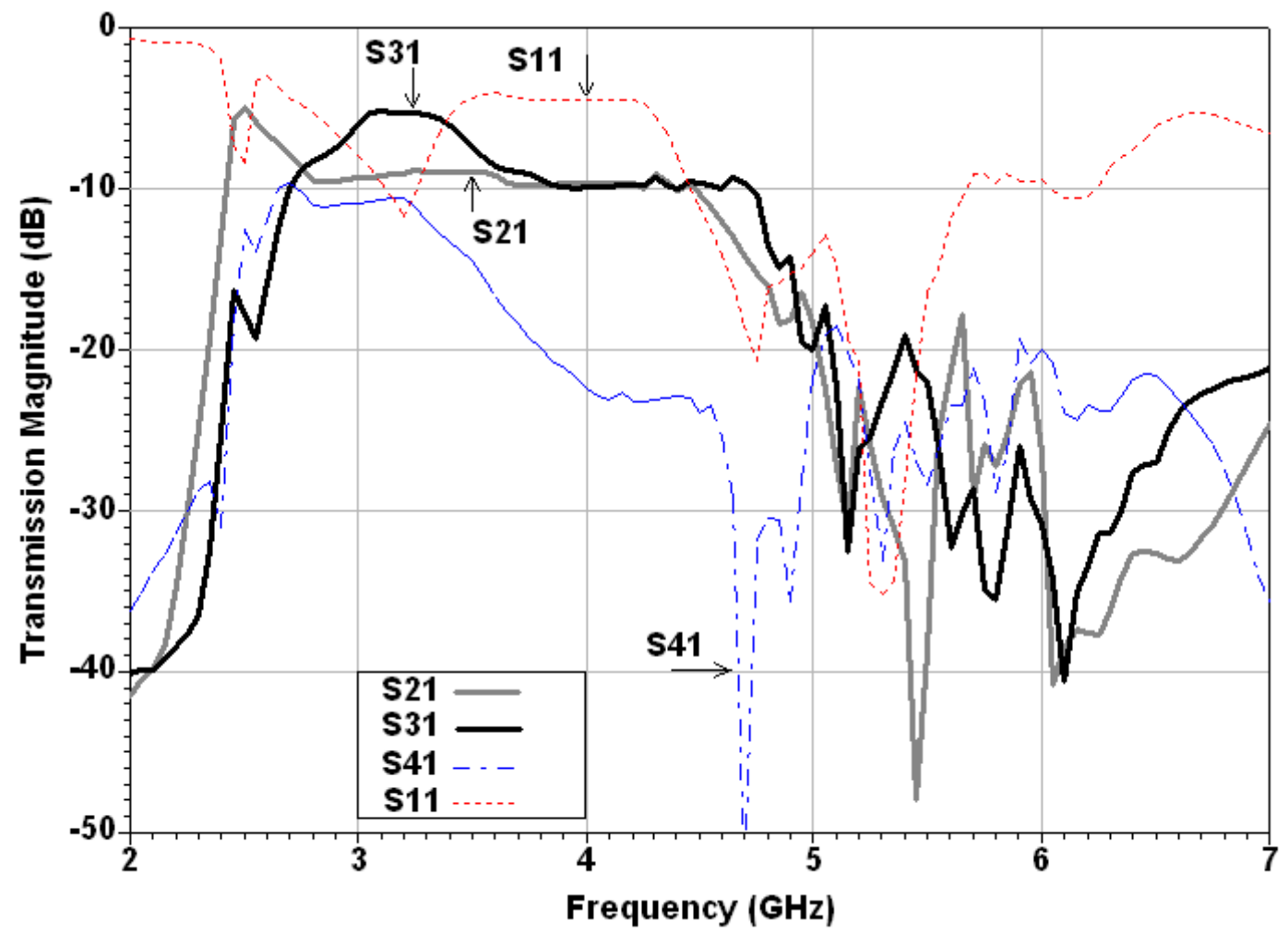

Fig. 9. The measured scattering parameters magnitudes of the ferrite CRLH coupled line coupler for $\mathrm{H}_{0}=1250$.

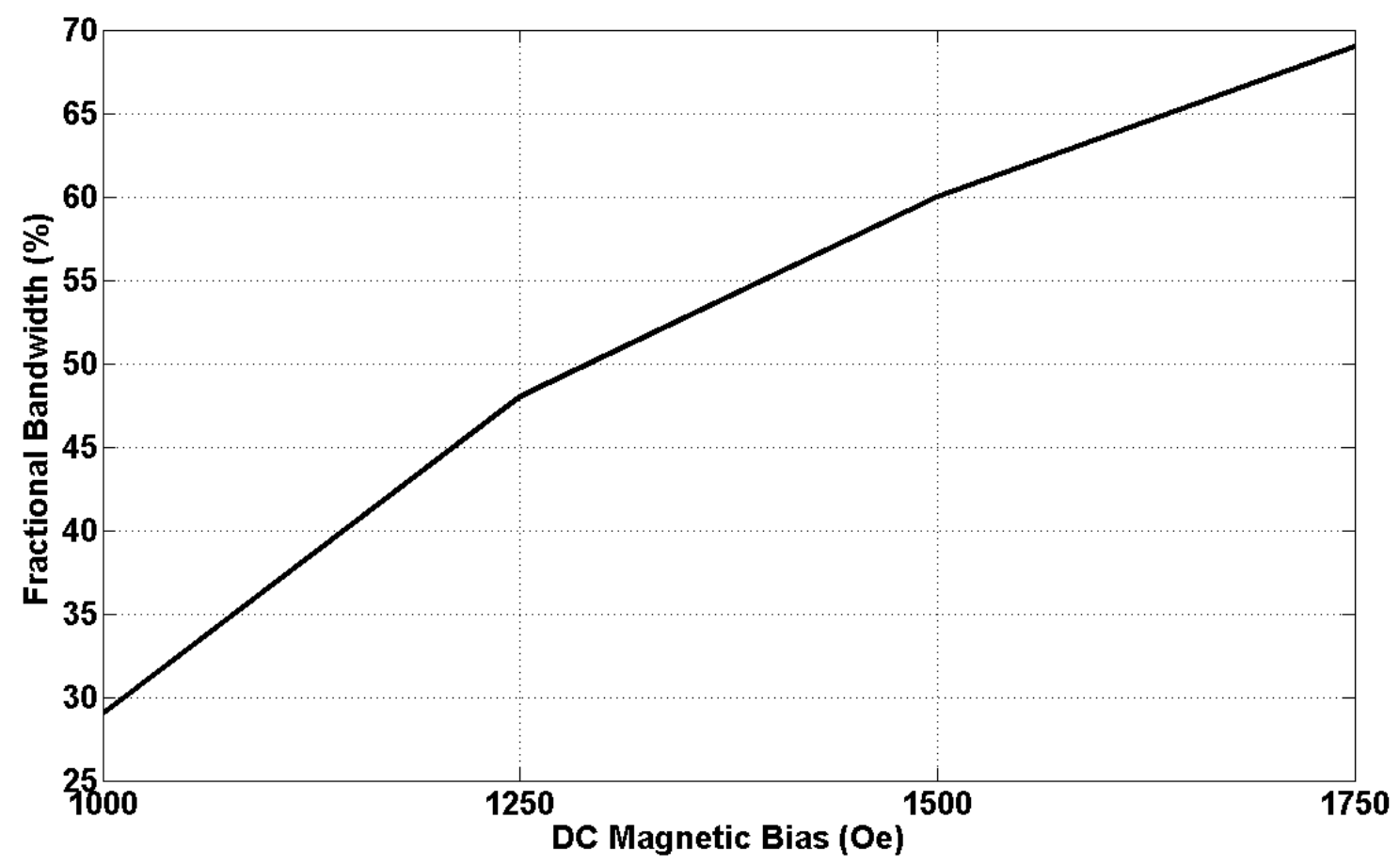

Fig. 10. The variation of the fractional bandwidth versus the internal DC magnetic bias $\left(\mathrm{H}_{0}\right)$. 
Table: 1 Comparison between recent published equal coupling couplers and proposed coupler

\begin{tabular}{|c|c|c|c|c|c|c|}
\hline Reference & $\begin{array}{c}\text { Miniaturization } \\
\text { Coupler Technique }\end{array}$ & $\begin{array}{c}\text { Substrate } \varepsilon_{\mathrm{r}} / \\
\text { thickness }(\mathrm{mm})\end{array}$ & $\begin{array}{c}\text { Frequency Band } \\
(\mathrm{GHZ})\end{array}$ & $\begin{array}{c}\text { Length } \times \\
\text { Width }\left(\mathrm{mm}^{2}\right)\end{array}$ & $\begin{array}{c}\text { Length } \times \text { Width }\left(\lambda_{\mathrm{g}}{ }^{2}\right. \\
\text { at center frequency) }\end{array}$ & $\begin{array}{c}\text { Tunable } \\
\text { Technique }\end{array}$ \\
\hline$[49]$ & $\begin{array}{c}\text { Coupled line section / } \\
\text { Branch line }\end{array}$ & $2.2 / 0.254$ & $0.7-1.2$ & $24.6 \times 15$ & $0.09 \lambda_{\mathrm{g}} \times 0.06 \lambda_{\mathrm{g}}$ & $\begin{array}{c}\text { Not } \\
\text { Tunable }\end{array}$ \\
\hline$[50]$ & $\begin{array}{c}\text { Asymmetric T } \\
\text { Junction / Rate Race }\end{array}$ & $3.38 / 0.508$ & $0.7-1.1$ & $22.7 \times 14.7$ & $0.1 \lambda_{\mathrm{g}} \times 0.07 \lambda_{\mathrm{g}}$ & $\begin{array}{c}\text { Not } \\
\text { Tunable }\end{array}$ \\
\hline$[51]$ & $\begin{array}{c}\text { Capacitive Loading } \\
{[52]}\end{array}$ & $10.2 / 1.27$ & $0.45 \%$ & $0.9-1.1$ & $0.24 \lambda_{\mathrm{g}} \times 0.18 \lambda_{\mathrm{g}}$ & $\begin{array}{c}\text { Tunable } \\
\text { Phase / } \\
\text { Varactor }\end{array}$ \\
\hline Branch Line Coupler \\
\hline N53]
\end{tabular}

\section{CONCLUSION}

Theoretical analysis and experimental measurements of the tunable ferrite CRLH CPW CLC has been presented and discussed in details. The two coupled CRLH lines function on ferrite substrate has been explained using the full wave analysis for forward and backward modes. The analysis confirms that a tunable coupler can be achieved by changing the applied DC magnetic bias to the ferrite substrate. The measurement results demonstrate that the fractional bandwidth of the CRLH CPW CLC can be tuned from $29 \%$ to $69 \%$ when the applied DC magnetic bias changes from 1000 Oe to 1750 Oe, verifying the theoretical prediction. A Moreover, the proposed CLC is very compact in size and requires low DC magnetic bias due to the low demagnetization factor of CPW configuration. Finally, comparison with recent tunable couplers confirms that the proposed coupler is competitive with them. The proposed coupler can be applied in tunable front end system. 


\section{REFERENCES}

[1] G. V. Eleftheriades and K. G. Balmain, Negative Refractive Metamaterials. New Jersey: John Wiey \& Sons, 2005.

[2] C. Caloz and T. Itoh, Electromagnetic Metamaterials Transmission Line Theory and Microwave Applications. New Jersey: John Wiey \& Sons, 2006.

[3] C. Caloz, and Tatsuo Itoh. "Metamaterials for high-frequency electronics."Proceedings of the IEEE, vol. 93, no. 10, 2005, pp. 1744-1752.

[4] H-X. Xu, G-M. Wang, X. Chen, and T. P.Li. "Broadband balun using fully artificial fractalshaped composite right/left handed transmission line." IEEE Microwave and Wireless Components Letters, vol. 22, no. 1, 2012, pp. 16-18.

[5] C. Damm, J. Freese, M. Schubler, and R. Jakoby. "Electrically controllable artificial transmission line transformer for matching purposes." IEEE transactions on microwave theory and techniques, vol. 55, no. 6, 2007, pp. 1348-1354.

[6] S. Mao and Y. Z. Chueh. "Broadband composite right/left-handed coplanar waveguide power splitters with arbitrary phase responses and balun and antenna applications." IEEE transactions on antennas and propagation 54, no. 1, 2006, pp. 243-250.

[7] J. Sorocki, I. Piekarz, K. Wincza, and S. Gruszczynski. "Right/left-handed transmission lines based on coupled transmission line sections and their application towards bandpass filters."IEEE Transactions on Microwave Theory and Techniques, vol. 63, no. 2, 2015, pp. 384-396.

[8] H. Lobato-Morales and A. Corona-Chávez, T. Itoh, and J. L. Olvera-Cervantes. "Dual-band multi-pole directional filter for microwave multiplexing applications." IEEE Microwave and Wireless Components Letters, vol. 21, no. 12, 2011, pp. 643-645.

[9] M. A. Hagag, and M. A. Abdalla. "Ultra compact CPW dual band filter based on $\pi$ generalized metamaterial NRI transmission line." Journal of Electromagnetic Waves and Applications, vol. 29, no. 8, 2015, pp. 1093-1103.

[10] H. V. Nguyen and C. Caloz, "Generalized coupled mode approach of metamaterial CLCs: coupling theory, phenomenological explanation, and experimental demonstration," IEEE Trans. Microwave Theory and Tech., vol. 55, pp. 1029-1039, May 2007.

[11] G. M. Shau and M. S. Mu, "A novel 3-dB directional coupler with broad bandwidths and compact size using composite right / left handed coplanar waveguide," IEEE Microwave and Wireless Components Lett., vol 17, pp. 331-333, May 2007.

[12] A. E. Fouda, A. Safwat, and H. El-Hennawy. "On the applications of the coupled-line composite right/left-handed unit cell." IEEE Transactions on Microwave Theory and Techniques, vol. 58, no. 6, 2010, pp. 1584-1591.

[13] R. Islam and G. V. Eleftheriades. "Review of the microstrip/negative-refractive-index transmission-line coupled-line coupler." IET microwaves, antennas \& propagation, vol. 6, no. 1, 2012, pp. 31-45.

[14] K. Murase, R. Ishikawa, and K. Honjo. "Group delay equalised monolithic microwave integrated circuit amplifier for ultra-wideband based on right/left-handed transmission line design approach." IET microwaves, antennas \& propagation, vol. 3, no. 6, 2009, pp. 967-973. 
[15] M. Abdalla, M. Abo El-Dahab, M. Ghouz, "Loaded Dipole Antennas with New CRLH Cell Configuration", AEU-Int. J Electron C, vol. 80, pp. 165-171, 2017.

[16] K. Yu, Y. Li, and X. L. Liu. "A high gain patch antenna using near zero-index metamaterial coating." In 2017 IEEE International Symposium on Antennas and Propagation, pp. 2175-2176. IEEE, 2017.

[17] K. Yu, Y. Li, and Y. Wang. "Multi-band metamaterial-based microstrip antenna for WLAN and WiMAX applications." In IEEE 2017 International Applied Computational Electromagnetics Society Symposium-Italy (ACES), pp. 1-2, 2017.

[18] M. A. Kenari, M. N. Moghadasi and R. A. Sadeghzadah, "The Resonating MTM Based Miniaturized Antennas for Wide-band RF-Microwave Systems" Microwave and Optical Technology Letters, vol. 57, no. 10, 2015, pp. 2339-2344.

[19] A. A. Jin Cheng, and M. Tsutsumi. "Double periodic composite right/left handed transmission line and its applications to compact leaky-wave antennas." IEEE Transactions on Antennas and Propagation, vol. 59, no. 10, 2011, pp. 3679-3686.

[20] M. A. Kenari, M. N-Moghadasi, R. A. Sadeghzadeh and B.S. Virdee, and E. Limiti, "New Compact Antenna Based on Simplified CRLH-TL for UWB Wireless Communication Systems", Int. J. of RF and Microwave Computer-Aided Engineering, vol. 26, no. 3, 2016, pp. 217-225.

[21] A. A. Ibrahim and M. A. Abdalla, "CRLH MIMO Antenna with Reversal Configuration", AEÜ - International Journal of Electronics and Communications, AEU-Int. J E;ectron C, vol. 70, no. 7, pp. 1134-1141,2016

[22] K. Yu, X. Liu, Mutual coupling reduction of a MIMO antenna array using 3-D novel meta-material structures, Applied Computational Electromagnetics Society Journal, vol.33, no.7, pp.758-763, 2018.

[23] H. X. Xu, G.-M. Wang, M. Q. Qi, Y.-Y. Lv, and X. Gao. "Metamaterial lens made of fully printed resonant-type negative-refractive-index transmission lines." Applied Physics Letters, vol. 102, no. 19, 2013, pp. 193502.

[24] H-X. Xu, S. Sun, S. T. Shaojie Ma, Q. He, G-M. Wang, T. Cai, H-P. Li, and L. Zhou. "Dynamical control on helicity of electromagnetic waves by tunable metasurfaces." Scientific reports 6 (2016): 27503.

[25] M. Tsutsumi and T. Ueda "Nonreciprocal left-handed microstrip lines using ferrite substrate," in Proc IEEE MTT-S Int. Symp., USA, 2004, pp. 249-253.

[26] M. Tsutsumi and T. Ueda "Left handed transmission characteristics of ferrite microstrip lines without series capacitive load," IEICE Trans. Electron., vol. E89, pp. 1318-1323, Sep. 2006.

[27] M. Abdalla, and Z. Hu, "On the study of CWP dual band left handed propagation with reciprocal and nonreciprocal characteristics over ferrite substrates," in Proc IEEE AP-S Int. Symp., USA, 2007, pp. 2578-2581.

[28] M. Abdalla, and Z. Hu, "Nonreciprocal left handed coplanar waveguide over ferrite substrate with only shunt inductive load," Microwave and optical technology lett, vol. 49, pp. 2810-2814, Nov. 2007. 
[29] T. Zhou, J. S. Zhou, Guo-hua Liu, Zhi-hua Dong, Zhi-qun Cheng, and Martine Le Berre. "Non-reciprocal CRLH transmission line on substrate YIG." 2015 IEEE $16^{\text {th }}$ Int. Conference in Communication Technology (ICCT), pp. 412-414.

[30] Y. J. Ueda, G. J. Wen, T. Q. Li, J.L. Li, K. Xie, "Design and Characterization of Tunable Terahertz Metamaterials With Broad Bandwidth and Low Loss", IEEE Antennas and Wireless Propagation Letters, vol. 11, 2012 pp. 264-267.

[31] S. Karimian, M. Abdalla and Z. Hu, "Tunable Metamaterial Ferrite Stepped Impedance Resonator (SIR)," 2010 PIERS The $27^{\text {th }}$ Progress in Electromagnetics Research Symposium, Mar. 22-26, 2010, Xi'an, China, pp 165-168.

[32] M. A. Abdalla and Z. Hu, "Compact Metamaterial Coplanar Waveguide Ferrite Tunable Resonator,"IET Microwaves, Antennas \& Propagation, vol. 10, no. 4, pp. 406-412, 2016.

[33] M. A. Abdalla and Z. Hu, "Multi-band functional tunable LH impedance transformer," Journal of Electromagnetic Wave and Applications, vol. 23, 2009, pp. 39-47.

[34] M. A. Abdalla and Z. Hu, "Compact tunable left handed ferrite transformer," International Journal of Infrared and Millimeter Waves, 2009,vol.30, no. 8, pp.813-825.

[35] M. Abdalla and Z. Hu "Ferrite Tunable Metamaterial Phase Shifter", 2010 IEEE AP-S International Antenna and Propagation Symposium Digest, Toronto, Cananda, pp. 1-4.

[36] T. Ueda, K. Ninomiya, K. Yoshida, and T. Itoh. "Design of dispersion-free phase-shifting non-reciprocity in composite right/left handed metamaterials." in 2016 IEEE MTT-S Int. Microwave Symposium (IMS), pp. 1-4.

[37] T. Kodera, and C. Caloz, "Integrated Leaky-Wave Antenna-Duplexer/Diplexer Using CRLH Uniform Ferrite-Loaded Open Waveguide", IEEE Trans. Antenna and Propagation vol. 58 , no. 8,2010 , pp. 2508-2514.

[38] M. Abdalla and Z. Hu, " Compact Novel CPW Ferrite Coupled Line Circulator with Lefthanded Power Divider/Combiner", 2011 European Microwave Week, EuMW2011, Digest, Manchester, UK, October 9-14 2011, pp. 794-797.

[39] G. Sajin, S. Simion, F. Craciunoiu, A.-C. Bunea, A. Dinescu, and A. A. Muller, "Ferrite supported steerable antenna on metamaterial CRLH transmission line", $40^{\text {th }}$ European Microwave Conference (EuMC), 20102010 , pp. 449-452.

[40] M. Abdalla and Z. Hu, " Compact and Tunable Metamaterial Antenna for Multi-band Wireless Communication applications", 2011 IEEE AP-S International Antenna and Propagation Symposium Digest, Jul. 2011, Spokane, USA, pp. 2951-2953.

[41] A. Porokhnyuk, T. Ueda, Y. Kado, Y.and T. Itoh, "Design of nonreciprocal CRLH metamaterial for non-squinting leaky-wave antenna" 2013 IEEE MTT-S International Microwave Symposium Digest (IMS), 2013, pp. 1-3.

[42] G. Sajin, I. A. Mocanu, F. Craciunoiu, M. Carp," MM-wave left-handed transmission line antenna on anisotropic substrate" $43^{\text {rd }}$ European Microwave Conference (EuMC), 2013, pp. 668-671.

[43] M. Tsutsumi and K. Okubo, "On the left handed ferrite coupled line," in EMTS Int. URSI Electromagnetic Theory Symposium Digest, Ottwa, Canda, 2007, pp. 1-3. 
[44] M. A. Abdalla and Z. Hu, "Compact tunable single and dual mode ferrite left-handed coplanar waveguide coupled line couplers,"IET Microwaves, Antennas \& Propagation, vol. 3, no. 4, 2009, pp. 695-702.

[45] M. A. Abdalla and Z. Hu, "Composite Right/Left-handed Coplanar Waveguide Ferrite Forward Coupled-Line Coupler,"IET Microwaves, Antennas \& Propagation, vol. 9, no. 10, 2015, pp. $1104-1111$.

[46] M.A. Abdalla and Z. Hu, "Reconfigurable/tunable dual band/dual mode ferrite composite right/left-handed CPW coupled-line coupler", Journal of Instrumentation, vol. 12, no. 9, pp. P09009.

[47] A. Ahorni "Demagnetizing factor for rectangular ferromagnetic prisms," Journal of Applied Physics, vol. 83, pp. 3432-3434, March 1998.

[48] M. Abdalla, "Ferrite left-handed meta-materials for RF microwave applications," Ph.D. dissertation, School of Electrical and Electronic Engineering, University of Mancheste, Manchester, UK, 2009.

[49] J. Kim, and J. G. Yook. "A Miniaturized 3 dB 90 Hybrid Coupler Using Coupled-Line Section With Spurious Rejection", IEEE Microwave and Wireless Components Letters, vol. 24, no. 11,2014 , pp. 766-768.

[50] C. H. Tseng and C. L. Chang, "A rigorous design methodology for compact planar branch-line and rat-race couplers with asymmetrical T-structures," IEEE Trans. Microw. Theory Tech., vol. 60, no. 7, 2012, pp. 2085-2092.

[51] H. Zhu and A. M. Abbosh. "A Compact Tunable Directional Coupler with Continuously Tuned Differential Phase." IEEE Microwave and Wireless Components Letters, vol. 28, no. 1, 2018, pp. 19-21.

[52] O. D. Gurbuz and G. M. Rebeiz, “A 1.6-2.3-GHz RF MEMS reconfigurable quadrature coupler and its application to a $360^{\circ}$ reflectivetype phase shifter," IEEE Trans. Microw. Theory Techn., vol. 63, no. 2, 2015, pp. 414-421.

[53] T. Zhang, and W. Che. "A compact reconfigurable coupler with tunable coupling coefficients and frequencies" IEEE Microwave and Wireless Components Letters, vol. 27, no. 2, 2017, pp. 129-131.

[54] F. Lin, "Compact Design of Planar Quadrature Coupler With Improved Phase Responses and Wide Tunable Coupling Ratios" IEEE Transactions on Microwave Theory and Techniques, vol. 66, no. 3, 2018, pp. 1263-1272. 